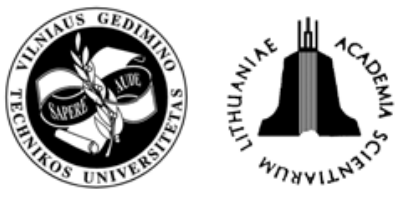

\title{
RESEARCH INTO THREE-COMPONENT BIODIESEL FUELS COMBUSTION PROCESS USING A SINGLE DROPLET TECHNIQUE
}

\author{
Laurencas Raslavičius ${ }^{1}$, Donatas Markšaitis ${ }^{2}$ \\ ${ }^{1}$ Lithuanian Institute of Agricultural Engineering, Lithuanian University of Agriculture \\ Instituto g. 20, LT-54132, Raudondvaris, Kaunas region, Lithuania \\ E-mail: laurencas.raslavicius@gmail.com; \\ ${ }^{2}$ Department of Transport Engineering, Kaunas University of Technology \\ Donelaičio g. 27, LT-44312, Kaunas, Lithuania \\ E-mail: donatas.marksaitis@ktu.lt
}

Received 11 April 2007; accepted 10 September 2007.

\begin{abstract}
In order to reduce the engine emission while at same time improving engine efficiency, it is very important to clarify the combustion mechanism. Even if, there are many researches into investigating the mechanism of engine combustion, so that to clarify the relationship between complicated phenomena, it is very difficult to investigate due to the complicated process of both physical and chemical reaction from the start of fuel injection to the end of combustion event. The numerical simulations are based on a detailed vaporization model and detailed chemical kinetics. The influence of different physical parameters like droplet temperature, gas phase temperature, ambient gas pressure and droplet burning velocity on the ignition delay process is investigated using fuel droplet combustion stand. Experimental results about their influence on ignition delay time were presented.
\end{abstract}

Keywords: single droplet technique, combustion mechanism, ignition delay time, dehydrated ethanol additive, fuel burning, multicomponent fuels.

\section{Introduction}

Great demands are being placed on energy production, especially with regard to environmental impact. Restrictions have been set on sulphur and nitrogen emissions from diesel engines and the Kyoto International Climate Convention limits carbon dioxide emissions. Finding new technological solutions to meet tightening emission targets creates new challenges in the development of new types of multicomponent ecological fuels. The objective is to minimise combustion emissions while, at the same time, increasing efficiency of fuels used. Accurate tests on combustion and burning is the key to achieving good chamber design. However, engine development gains significantly not only from tests, but also from experiments using a single droplet technique to identify the ignition delay time of various types of fuels, which characterizes burning properties. This kind of experiments can replace expensive trials and tests requiring stringent and difficult controls, saving millions of euros each year.

A multicomponent droplet $[1,2]$ is known to exhibit a significantly different gasification behavior compared with that of a pure fuel droplet. These differences have been attributed [2-7] to transient liquid mass transport in the droplet interior, volatility differential between the constituent fuels, phase equilibrium at the droplet surface, and thermo-transport properties that are functions of mixture composition, temperature, and pressure. In order to address these complex issues for fuels in a systematic manner, we have taken the first step, i.e., to study the combustion behavior of a multicomponent fuel droplet using a fuel droplet combustion stand.

Combustion of single fuel droplets of dehydrated ethanol (A), Rapeseed methyl ester (RME), diesel fuel (MD) and their blends of various proportions were studied.

\section{Objects and methods}

In the diesel engine the liquid fuel is injected into the heated compressed air, the temperature of which is 773$873 \mathrm{~K}$. Sprayed fuel takes a semblance of fog. However experimentally to investigate burning peculiarities of such a small fraction using classic methods is impossible.

For the experiment we used several times bigger, one-sized droplets of unmixed fuels and also their blends of various proportions. Because of the increased fuel droplet mass, it was imposible to watch combustion process at the imitated experiment temperature equal to combustion chamber. The droplet simply evaporates. This problem was solved by increasing ambient tempera- 
ture $(900-1100 \mathrm{~K})$ to identify ignition delay time of the investigated fuel samples.

Single suspended droplet technique, collectively developed by the Institute of Combustion \& Advanced Technologies, the Odessa State I. I. Mechnikov University (Ukraine) and Lithuanian Institute of Agricultural Engineering, Lithuanian University of Agriculture (Lithuania), was used for the droplet combustion tests on different fuel samples and blends of different composition.

Investigated liquid fuel droplet was settled with the help of medicine syringe on the suspension device (2), manufactured from glass yarn and having a $800 \mu \mathrm{m}$ radius ball (3) on the end. At the time of experimental measuring, heated furnace (1) was pushed via deflective rails towards suspension device in the way, that the distance between fuel droplet and thermo-couple was $2-3 \mathrm{~mm}$. This distance was controlled by synchronising contacts (6) which also operate a stopwatch (7) switch-on. Droplet combustion control was provided by optical system, equipped with radiant (8), screen (9) and binoculars (10) (Fig. 1).

Research into fuel droplet combustion process was performed according to the following methodology. Furnace was heated until initial temperature $T_{\infty}=900 \mathrm{~K}$. Fuel droplet (see Fig. 2) with radius $r_{0}=1,125 \pm 0,05 \mathrm{~mm}$ was settled on the glass yarn with the help of medicine syringe. Droplet size was variable with the sprayed fuel volume and controlled looking through binoculars at the graduated screan where droplet reflection is visible. Initial fuel droplet temperature was $T_{0}=293 \mathrm{~K}\left(T_{0}=20^{\circ} \mathrm{C}\right)$.

Fuel droplet hanging on the suspension device assumes vertically outstretched form. This peculiarity causes a necessity to measure droplet vertical dimension. After the fixing of exact droplet size, furnace was secured atop to console of suspension device. In this way a horizontal part of suspension device appears inside the furnace and the suspended droplet position is coincident with the centre of furnace. A time that it took the droplet to reach the centre of furnace (2-3 mm from thermo-couple) did not exceed $0,5 \pm 0,05 \mathrm{~s}$. This moment synchronized a swich-on of the stopwatch. Interval between fuel droplet reaching the centre of furnace and appearing of flame around the droplet was fixated as ignition delay time $\tau_{\text {ind }}$.

A stopwatch also fixated a total time of droplet existence. Droplet burning time was calculated as a difference between total time of droplet existence and ignition delay time. Thermo-couple inflexible mounted into the back-wall of furnace fixated droplet combustion temperature. Measurement error did not exceed $\pm 5 \mathrm{~K}$.

When the droplet burnt out, the furnace was pulling away via deflective rails. Experiment with the same type of fuel sample was repeated 5-10 times at the same value of ambient temperature. Ignition delay time identifying experiment continued with increasing ambient temperature from $10 \mathrm{~K}$ step by step to $1100 \mathrm{~K}$, performing the same procedures. Experiment error is scheduled as $2-3 \%$.

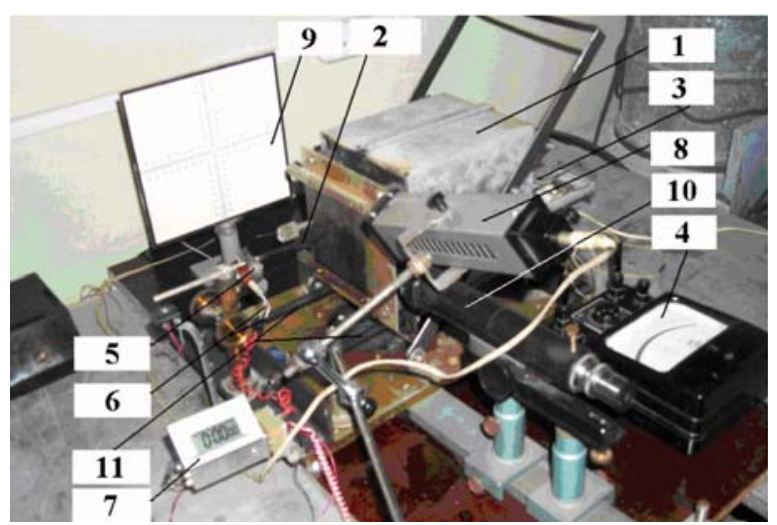

Fig. 1. Fuel droplet combustion stand scheme: 1 - furnace, 2 - suspension device, 3 - ambient temperature measuring sensor, 4 - potentiometer, 5 - photoelectric cell,

6 - synchronising contacts, 7 - stopwatch, 8 - radiant, 9 - screen, 10 - binoculars, 11 - deflective rails

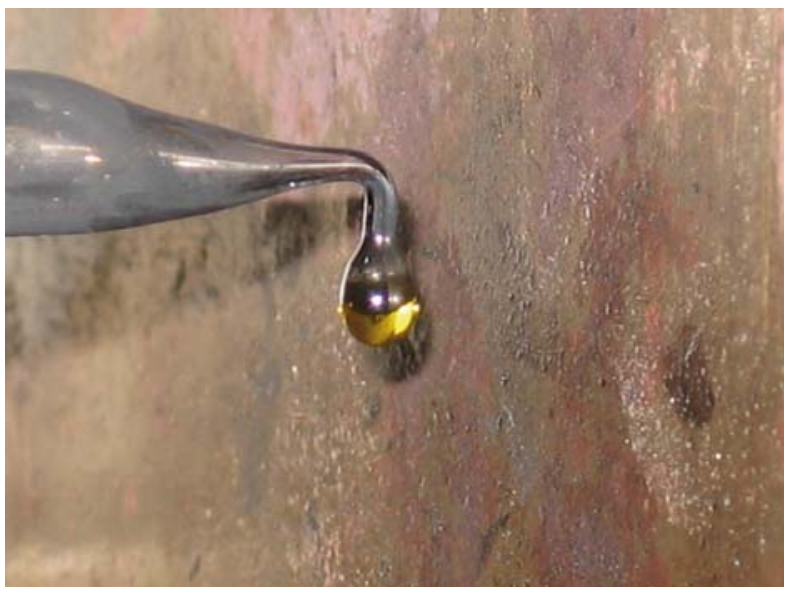

Fig. 2. Fuel droplet hanging on the suspension device

After completing experiments with one sample in all temperature ranges, that type of fuel was replaced with another one.

\section{Results and discussion}

While analyzing experimental data results (Table 1, Fig. 3) it is evident that single droplet ignition delay time of mineral diesel fuel (MD) marginally exceeds or is equal to analogous index of RME until the temperature $T_{\infty}=945 \mathrm{~K}$ what is not coincident with the earlier done $\tau_{\text {ind }}$ calculations using a quasistationary model. Though, forthcoming enlargement of temperature reversed this relation. Under a temperature $T_{\infty}=955 \mathrm{~K}$ and $965 \mathrm{~K}$ ignition delay time of MD fuel droplet decreased to $12-18 \%$ comparing to the RME droplet of the same radius. To verify whether this tendency endures at the higher values of temperature became impossible, because droplets of RME fall dawn from suspension device before the combustion process begins. We can observe combustion process of MD droplets at even higher temperature volumes, until $1005 \mathrm{~K}$. This can be explained that liquid RME has a slightly upper value of density than MD and a likely harder surface tension coefficient depending on temperature. 
Table 1. Experimental data on MD and RME single droplet ignition delay time reliance upon ambient temperature. Initial droplet radius $r_{0}=1,125 \mathrm{~mm}$

\begin{tabular}{|c|c|c|c|c|}
\hline \multirow{2}{*}{$T_{\infty}, \mathrm{K}$} & \multicolumn{2}{|c|}{$\mathrm{RME}$} & \multicolumn{2}{c|}{$\mathrm{MD}$} \\
\cline { 2 - 5 } & $\tau_{\text {ind }}, \mathrm{s}$ & $\Delta \tau_{\text {ind }}, \mathrm{s}$ & $\tau_{\text {ind }}, \mathrm{s}$ & $\Delta \tau_{\text {ind }}, \mathrm{s}$ \\
\hline 860 & 5.39 & \pm 0.15 & - & - \\
\hline 875 & 4.98 & \pm 0.20 & - & - \\
\hline 885 & 4.80 & \pm 0.12 & - & - \\
\hline 895 & 4.75 & \pm 0.09 & - & - \\
\hline 905 & 4.38 & \pm 0.05 & - & - \\
\hline 910 & 4.30 & \pm 0.07 & 4.59 & \pm 0.20 \\
\hline 915 & 4.18 & \pm 0.08 & 4.50 & \pm 0.14 \\
\hline 925 & 4.00 & \pm 0.07 & 4.23 & \pm 0.15 \\
\hline 935 & 3.92 & \pm 0.10 & 4.03 & \pm 0.10 \\
\hline 945 & 3.78 & \pm 0.06 & 3.68 & \pm 0.07 \\
\hline 955 & 3.73 & \pm 0.05 & 3.32 & \pm 0.10 \\
\hline 965 & 3.68 & \pm 0.10 & 3.13 & \pm 0.15 \\
\hline 975 & - & - & 3.02 & \pm 0.05 \\
\hline 985 & - & - & 2.70 & \pm 0.07 \\
\hline 995 & - & - & 2.55 & \pm 0.09 \\
\hline 1005 & - & - & 2.39 & \pm 0.12 \\
\hline
\end{tabular}

Continuing experiments of measuring MD ignition delay time near the edge of inflammation, when fuel droplet before the moment of combustion has almost evaporated, many times we observe appearing of irradiant blue zone of inflammation outermost from suspension device, near-by the internal walls of furnace. Irradiant blue zone appeared at distance approximately equal to 30 initial droplet radius. This fact proves theoretical study results about liquid fuel droplet ignition delay time analysis in near the critical conditions [8].

We must admit that critical temperature of $\mathrm{MD}$ showed the higher value comparing to RME, $910 \mathrm{~K}$ and $860 \mathrm{~K}$, accordingly. This result coincides very well with the data presented by various authors in their works about estimation of ignition delay time of MD and RME, where single droplet radius does not exceed $r_{0}=1 \mathrm{~mm}$.

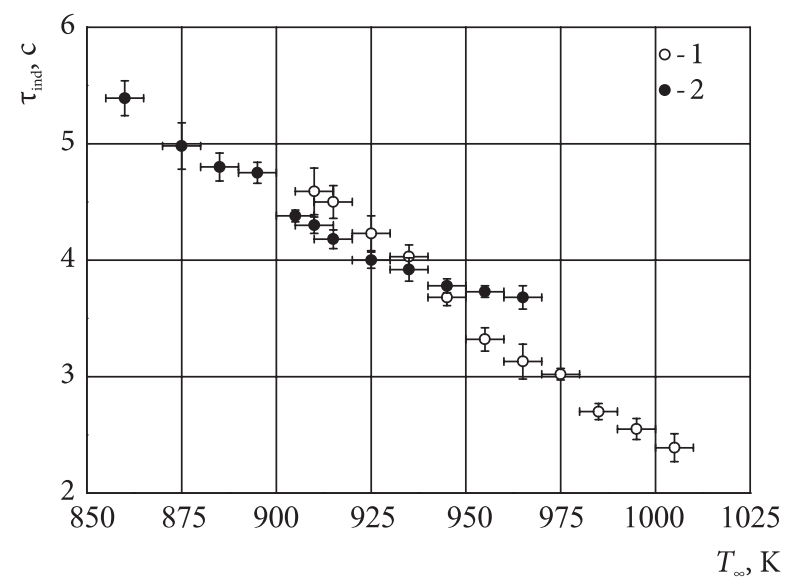

Fig. 3. Single droplet ignition delay time reliance on ambient temperature: 1 - diesel fuel (MD), 2 - RME. Initial droplet radius $r_{0}=1,125 \mathrm{~mm}$
Combustion experiments were performed using chromium-aluminium thermo-couple.

In this way, ignition delay time calculations of $\mathrm{MD}$ and RME droplets using a quasistationary model qualitatively concur with experimental results, beginning from temperature $T_{\infty}=955 \mathrm{~K}$ and above. This value exceeds the critical inflammation temperature of RME by 95 degrees.

One more significant conclusion sequential from the quasistationary model calculations of single droplet ignition delay time analysis - additive of dehydrated alcohol (A) to MD and RME reduces ignition delay time $\tau_{\text {ind }}$ volume of mentioned fuels. And the opposite - enlarging RME percental amount in the basic fuel blend causes an icrease of $\tau_{\text {ind }}$ volume.

With the intention to verify this tendency we carried out a series of experiments with several fuel blends: $100 \% \mathrm{MD}+5 \% \mathrm{~A}, 100 \% \mathrm{RME}+5 \% \mathrm{~A}, 90 \% \mathrm{MD}+$ $10 \% \mathrm{RME}$ and $90 \% \mathrm{MD}+10 \% \mathrm{RME}+5 \% \mathrm{~A}$.

Experimental results proved that small additive quantities to the basic fuel blends practically do not cause critical inflammation conditions. Above mentioned investigated fuel blends showed critical inflammation temperature measurement results, which did not exceed experimental error limits.

Obtained findings about diesel fuel and MD/RME blends with dehydrated alcohol (A) additive and also the single droplet ignition delay time evaluation are presented in Table 2 as compared to calculated ones using a quasistationary model (ambient temperature $T_{\infty}=965 \mathrm{~K}$ ).

Table 2. Single droplet ignition delay time measurement results for the various types of fuels. Initial droplet radius $r_{0}=1,125$ $\mathrm{mm}\left(\tau_{\text {ind }}, \mathrm{s}^{\star}-\right.$ quasistationary model data, $\Delta \tau_{\text {ind }}-$ absolute measurement error, $\varepsilon$ - comparative measurement error)

\begin{tabular}{|l|c|c|c|c|}
\hline \multicolumn{1}{|c|}{ Fuel type } & $\tau_{\text {ind }}, \mathrm{s}^{*}$ & $\tau_{\text {ind }}, \mathrm{s}$ & $\Delta \tau_{\text {ind }}, \mathrm{s}$ & $\varepsilon \%$ \\
\hline $100 \% \mathrm{MD}$ & 4.39 & 3.13 & \pm 0.15 & 4.8 \\
\hline $100 \% \mathrm{RME}$ & 7.67 & 3.68 & \pm 0.10 & 2.7 \\
\hline $100 \% \mathrm{MD}+5 \% \mathrm{~A}$ & 4.23 & 2.68 & \pm 0.25 & 9.5 \\
\hline $100 \% \mathrm{RME}+5 \% \mathrm{~A}$ & 6.03 & 3.29 & \pm 0.15 & 4.5 \\
\hline $90 \% \mathrm{MD}+10 \% \mathrm{RME}$ & 4.57 & 3.29 & \pm 0.07 & 2.1 \\
\hline $90 \% \mathrm{MD}+10 \% \mathrm{RME}+5 \% \mathrm{~A}$ & 4.39 & 3.06 & \pm 0.09 & 2.8 \\
\hline
\end{tabular}

It is evident, that presented in Table 2 experimental data qualitatively fit in with the quasistationary model results very well. Moreover, we must admit that small quantities of dehydrated alcohol (A) additive to mineral diesel fuel, affect single droplet ignition delay time almost two times better than RME additive to MD (Figs. 4, 5).

While using an integrated RME/A additive to mineral diesel fuel, ignition delay time $\tau_{\text {ind }}$ of such a threecomponent fuel blend approximates to the values of pure $\mathrm{MD}$ (Fig. 6).

\section{Conclusions}

1. Experimental data qualitatively fit in with the quasistationary model results very well beginning from the ambient temperature $T_{\infty}=965 \mathrm{~K}$ and above. 


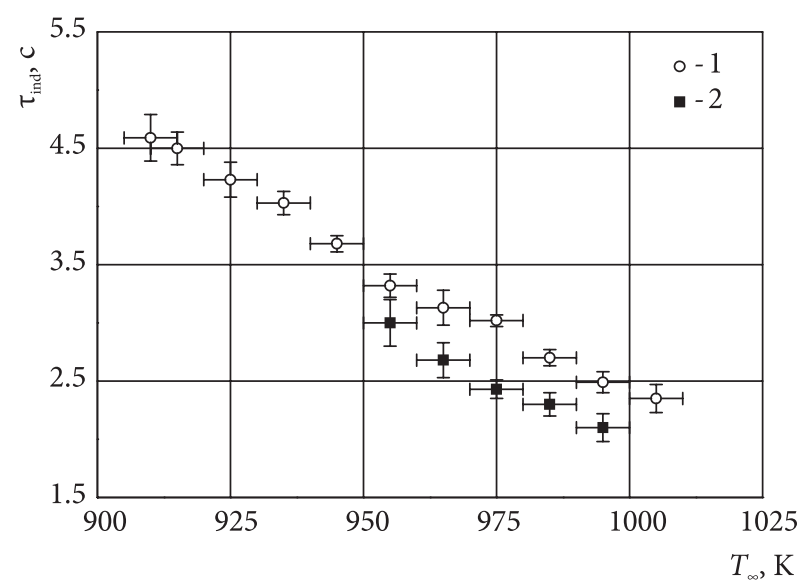

Fig. 4. Single droplet ignition delay time reliance on ambient temperature: 1 - diesel fuel (MD), 2 - two-component fuel blend (100\% MD+5 \% A)

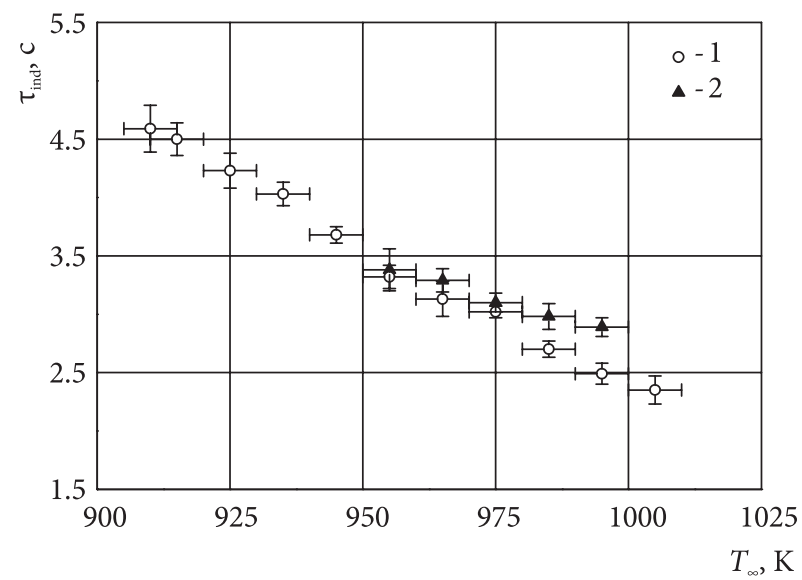

Fig. 5. Single droplet ignition delay time reliance on ambient temperature: 1 - diesel fuel (MD), 2 - two-component fuel blend (90\% MD+10 \% RME)

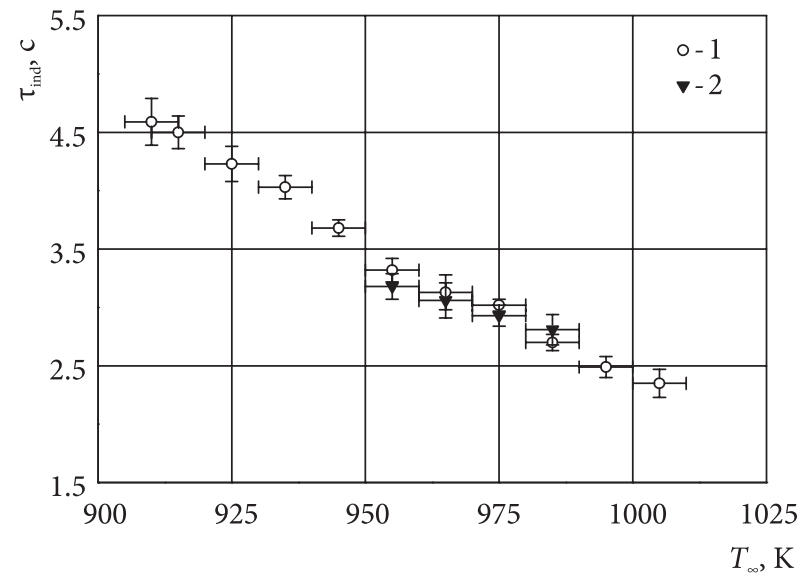

Fig. 6. Single droplet ignition delay time reliance on ambient temperature: 1 - diesel fuel (MD), 2 - three-component fuel blend $(90 \% \mathrm{MD}+10 \% \mathrm{RME}+5 \% \mathrm{~A})$
2. This value exceeds the critical inflammation temperature of RME by 95 degrees.

\section{References}

1. NEWBOLD, F. R.; AMUNDSON, N. R. A Model for evaporation of a multicomponent droplet. Journal of American Institute of Chemical Engineering, 1973, p. 22-30.

2. RUSZALO, R.; HALLETT, W. L. A Model for the autoignition of single liquid droplets at high pressure. Journal of Combustion Science and Technology, 1992, p. 183-197.

3. LAW, C. K. Recent advances in droplet vaporization and combustion. Journal of Progress in Energy and Combustion Science, 1982, p. 169-195.

4. CANADA, G. S.; FAETH, G. M. Fuel droplet burning rates at high pressures. In Proceedings of the Combustion Institute, 1974, p. 1345-1354.

5. ABRAMZON, B.; SIRIGNANO, W. A. Droplet vaporization models for spray combustion calculations. International Journal of Heat Mass Transfer, 1989, No. 9, p. 16051618.

6. CHEN, G.; AGGARWAL, S. K.; JACKSON, T. A.; SWITZER, G. L. Experimental study of pure and multicomponent fuel evaporation in a heated air flow. International Journal of Atomization Sprays, 1997, p. 317-337.

7. AGGARWAL, S. K. Ignition behavior of a dilute multicomponent fuel Spray. Journal of Combustion and Flame, 1989, p. 5-15.

8. BLOSHENKO, V. N.; MERZHANOV, A. G.; PEREGUDOV, I.; HAJKIN, B. I. Towars theory of the gaseous phase droplet combustion. Combustion and Flame (Горение u взрыв), Moscow: Nauka, 1973, p. 227-233 (in Russian). 